\title{
Classic papers: using Google Scholar to detect the highly-cited documents
}

\author{
Enrique Orduna-Malea*, Alberto Martín-Martín ${ }^{* *}$ and Emilio Delgado López-Cózar** \\ *enorma@upv.es \\ Universitat Politècnica de València, Camino de Vera s/n, 46022 (Spain) \\ **albertomartin@ugr.es; edelgado@ugr.es
}

Facultad de Comunicación y Documentación, Universidad de Granada, Colegio Máximo de Cartuja s/n, 18071

(Spain)

\begin{abstract}
In June 2017 Google Scholar launched a new product called Classic Papers. This service currently displays the most cited English-language original research articles by fields and published in 2006. The main goal of this work is to describe the foremost features of this new service, as well as to highlight its main strengths and weaknesses. To do this, a total of 2,515 records were extracted. For each record, bibliographic data (broad subject category and subcategory; Title of the document; URL; Authors, Google Scholar Citation profiles' URL; Citations received) were gathered. It is finally concluded that, although the product is easy to use and provides original data about highly cited documents at the level of disciplines, it still suffers of some methodological concerns (related to the subject classification of documents and the use of homogenous visualization threshold regardless the discipline) that jeopardizes the utility of this product for bibliometric purposes.

\section{Origins of the Citations Classics}

In 1969 Garfield had already compiled a list of the top 50 most cited articles published in 1967 (Figure 1). In that list he already used the term "classics" to refer to those highly cited documents. Six years later he prepared a similar list, but this time about articles published between 1961 and 1972. This list comprised the top 50 most cited articles published in that period, and he again used the term "classics" to refer to those works.
\end{abstract}


Figure 1. Most cited articles published in 1967 (Garfield, 1971).

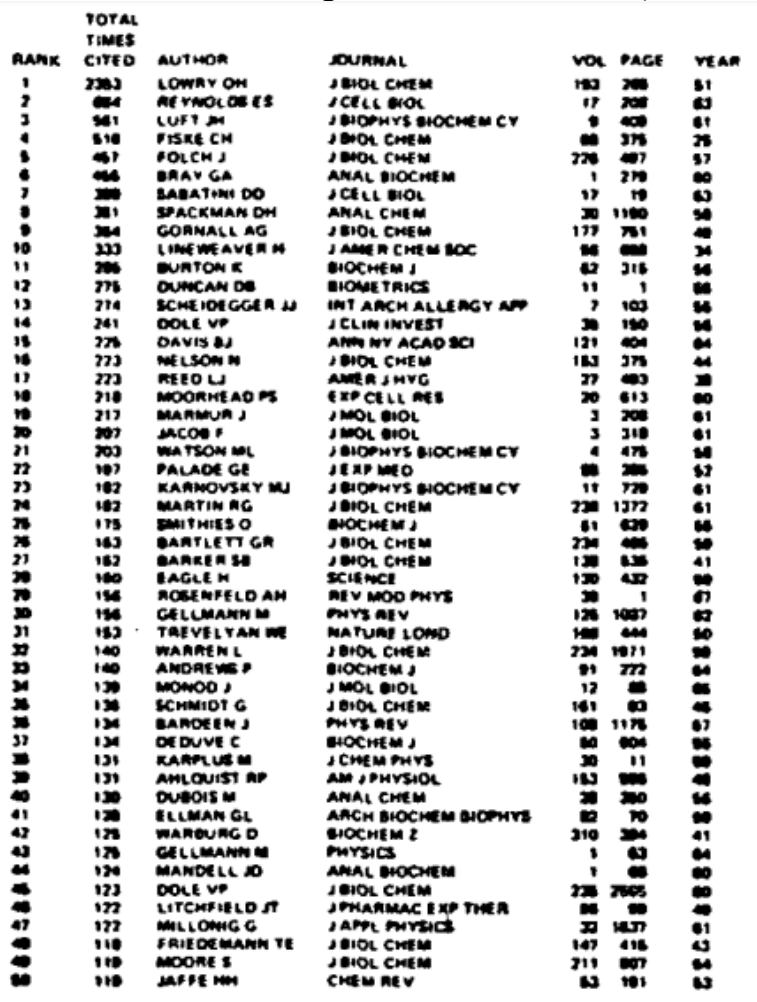

Garfield revisited this topic repeatedly in the following years. No less than 17 essays about the "citation classics" of various scientific fields or journals were published, and some of them stimulated a discussion on the meaning and influence of this kind of studies (immortality, obliteration, productivity, genre, Nobel prizes...). Other essays (more than 80) were dedicated to examining the most cited papers, books, and authors in various disciplines, specialties, journals, or countries. On top of this foundation, Thomson Scientific first, Thomson Reuters later, and Clarivate Analytics today, built the Essential Science Indicators (ESI), which every year presents the most cited documents of the last decade.

While the use of highly-cited documents in research evaluation has been studied, the conditions that determine whether a document can be considered highly-cited are not yet globally agreed (Bornmann, 2014).

\section{Google Scholar's Classic Papers}

The appearance of Google Scholar opened up new possibilities in this field. Its birth in 2004 signalled a revolution in the way scientific publications were searched, retrieved and accessed (Orduna-Malea, Martín-Martín, Ayllón, \& Delgado López-Cózar, 2016). The capacity of Google Scholar to identify highly-cited documents has been already treated in the literature (Martín-Martín, Orduna-Malea, Harzing, \& Delgado López-Cózar, 2017).

Since June 2017, Google started providing a new service called Classic Papers (GSCP), which contains lists of highly-cited documents by discipline: the top 10 most cited Englishlanguage original research articles published in 2006 in 252 subject categories, according to the data available in Google Scholar as of May 2017. In July of 2018 Google Scholar Metrics was updated, but a new version of Classic Papers was not released. Furthermore, the link to

\footnotetext{
${ }^{1}$ All of them available at http://garfield.library.upenn.edu/citationclassicessays.html
} 
the 2017 edition of Classic Papers was removed from the interface, although the product is still accessible ${ }^{2}$.

The criteria used by this product to include highly-cited documents are the following:

- $\quad$ They must have been published in 2006

- They must be journal articles, articles deposited in repositories, or conference communications.

- They must describe original research. Review articles, introductory articles, editorials, guides, commentaries, etc. are explicitly excluded.

- They must be written in English.

- They must be among the top 10 most cited documents in their respective subject category.

- $\quad$ They must have received at least 20 citations.

The goal of this study is to assess this new product in order to gauge its reliability and validity for identifying highly-cited documents, and to find its main strengths and weaknesses.

\section{Methods}

We first extracted all the information available in GSCP. For this purpose, a custom script was developed which scraped all the relevant information, and saved it as a table in a spreadsheet file. The information extracted was:

- $\quad$ Broad subject categories and subcategories.

- Bibliographic information of the documents, including:

○ Title of the document, and URL pointing to the corresponding Google Scholar record.

O Authors (including URL to Google Scholar Citations profile when available), name of the publication venue, and year of publication.

- Name and URL to Google Scholar Citations profile of showcased author.

- Number of citations the document had received (as of May 2017).

A total of 2,515 records were retrieved by July 2017.

\section{Results}

Data visualization

Articles are classified in 294 subject categories, which in turn are grouped in eight broad scientific areas (Table 1). Since there are 42 subject categories appearing in two broad scientific areas, there are 252 unique subject categories.

\footnotetext{
${ }^{2} \mathrm{https}$ ://scholar.google.com/citations?view_op=list_classic_articles\&hl=en\&by=2006
} 
Table 1. Number of subject categories in each broad scientific area in GSCP.

\begin{tabular}{|l|c|}
\multicolumn{1}{|c|}{ Areas } & $\begin{array}{c}\text { Number of } \\
\text { subject categories }\end{array}$ \\
\hline Health \& Medical Sciences & 68 \\
\hline Engineering \& Computer Science & 57 \\
\hline Social Sciences & 51 \\
\hline Life Sciences \& Earth Sciences & 38 \\
\hline Humanities, Literature \& Arts & 25 \\
\hline Physics \& Mathematics & 23 \\
\hline Chemical \& Material Sciences & 17 \\
\hline Business, Economics \& Management & 15 \\
\hline
\end{tabular}

Each of these 252 categories presents 10 articles, except French Studies, which only has 5 with at least 20 citations, which is the self-imposed minimum used by Google Scholar. That is the reason why the total number of articles is 2,515 instead of 2,520 (252 times 10).

One of the innovative aspects of the product is that it displays the link to the Google Scholar Citations profile of some of the authors of the article. 31\% of the articles (654) displayed in GSCP lack such a link, and there are significant differences among disciplines. For example, in 'Chemical \& Material Sciences', 5 out of the 17 subdisciplines considered (0.29\%) display links to author profiles for all documents included in the subdiscipline, whereas in 'Humanities, Literature \& Arts', in none of the 25 subcategories can we find at least one author with a public profile for each of the 10 documents (Table 2).

Table 2. Subcategories with at least one document whose author is linked to an author profile

\begin{tabular}{lrrr}
\hline Category & Subcategories & SWP & $\%$ \\
\hline Life Sciences \& Earth Sciences & 38 & 7 & 0,18 \\
Business, Economics \& Management & 15 & 4 & 0,27 \\
Chemical \& Material Sciences & 17 & 5 & 0,29 \\
Engineering \& Computer Science & 57 & 15 & 0,26 \\
Humanities, Literature \& Arts & 25 & 0 & 0,00 \\
Health \& Medical Sciences & 68 & 6 & 0,09 \\
Physics \& Mathematics & 23 & 3 & 0,13 \\
Social Sciences & 51 & 5 & 0,10 \\
\hline TOTAL & 294 & 45 & \\
\hline
\end{tabular}

Table 3 shows the subcategories in which there is a higher number of highly-cited documents for which no author profile is available. As we can observe, 'American Literature \& Studies' and, unexpectedly, 'Plastic \& Reconstructive Surgery', are at the top of this list.

Table 3. Subcategories in GSCP in which most of the documents are written by authors that haven't set up a public Google Scholar Citations profile. 


\begin{tabular}{|l|c|}
\multicolumn{1}{|c|}{ Subcategories } & $\begin{array}{c}\text { Number of papers for } \\
\text { which no author has } \\
\text { a public GSC profile }\end{array}$ \\
\hline American Literature \& Studies & 9 \\
\hline Plastic \& Reconstructive Surgery & 9 \\
\hline Drama \& Theater Arts & 8 \\
\hline International Law & 8 \\
\hline African Studies \& History & 7 \\
\hline Dentistry & 7 \\
\hline Ethnic \& Cultural Studies & 7 \\
\hline Literature \& Writing & 7 \\
\hline Visual Arts & 7 \\
\hline
\end{tabular}

Most of the articles displayed in GSCP are written in collaboration by several co-authors, and even if more than one has a public Google Scholar Citations profile, only one is prominently displayed in the record. The system seems to give preference to the first author, then to the last author, and if neither of these have a profile, it selects whatever profile is available first according to author order.

Reliability and validity

There are four critical aspects about which we should know more precise information.

\section{1) What does GSCP understands as a research article?}

Although they declare that they are "...articles that presented new research"3, we ask: how have they identified research articles from those that are not research articles? What constitutes an introductory article and how have they identified them? What do they mean when they add a disconcerting "etc." when they list the excluded document types? "Etc." is rarely admissible in Science, where all explanations should be precise. This issue is important because it may be the case that some articles that don't meet these requisites have been included, or the opposite, that some articles that do meet the requisites are missing.

It is important to remember that defining the typology of a document is not an easy task, and that even traditional bibliographic databases like Web of Science or Scopus have not been able to solve this issue completely. There are many discrepancies in how each of these databases defines the typology of the documents they cover. This happens frequently with review articles. There are also abundant internal inconsistencies in the databases.

\section{2) Subject classification of the articles}

This task involves assigning each article to one of 252 subject categories, and it is a crucial issue for the correct development of the product, but also very thorny. There are two fundamental questions we may ask regarding this issue:

a) Which criteria have they adopted to carry out the subject classification?

It seems clear that the classification scheme they have selected is the same they use in Google Scholar Metrics, their annual ranking of scientific journals. The only difference is the elimination of eight subject categories ('Physics \& Mathematics'; 'Business,

\footnotetext{
${ }^{3}$ https://scholar.googleblog.com/2017/06/classic-papers-articles-that-have-stood.html
} 
Economics \& Management'; 'Chemical \& Material Sciences'; 'Health \& Medical Sciences'; 'Engineering \& Computer Science'; 'Life Sciences \& Earth Sciences'; 'Social Sciences'; 'Humanities, Literature \& Arts') which are referred to as "general", because their title is the same as the broad scientific area where they are included.

At first, the elimination of these categories should not pose any problem, because the journals included in those categories are also classified in other subject categories (sometimes up to four other). However, there are journals which are only classified in these generic categories. Have the articles published in these journals been classified in other subject categories?

We have checked that articles published in multidisciplinary journals (such as Nature, Science, or PNAS) have been indeed classified ad hoc in their respective subject categories according to the topic of the articles. It seems that the articles published in journals with a broad scope have also been classified in the correct subject categories (Journal of the American Chemical Society, IEEE Transactions on Industrial Electronics, The New England Journal of Medicine, JAMA, The Lancet, Qualitative Inquiry, Scientific Reports, PLoS Biology, Reviews of Modern Physics, Procedia-Social and Behavioral Sciences).

b) How have they classified the articles published in multidisciplinary journals and journals with a broad scope?

Most services rely on journal-level classifications instead of article-level classifications. Recently Dimensions database started classifying at the level of contributions with some inconsistencies detected (Orduna-Malea \& Delgado López-Cózar, 2018). In this sense, how has Google Scholar solved this problem? In most cases articles are simply assigned to the same categories where the journal has been classified, without paying attention to the actual topic of the article.

This approach, the most commonly used in bibliometrics, is ill-suited for multidisciplinary journals and the other journals with a broad scope that are published in most disciplines. It is known that the ESI classifies multidisciplinary articles according to the subject categories of the journals publishing the articles that cite them as well as to the journals of the articles cited by them, an incontrovertible approach.

\section{3) How does Google Scholar handle document versions?}

Can we be sure they have successfully merged together all the versions indexed in Google Scholar of these documents? Otherwise, the citation counts of the documents might be scattered in several records.

Previous studies have shown that this is an important issue when we are talking about highlycited articles (Martín-Martín, Ayllón, Delgado López-Cózar, \& Orduna-Malea, 2015). It seems, as Figure 2 evidences, that there are still some records that refer to the same highlycited documents that appear in GSCP which haven't been merged with the main record (the one with the most citations).

Figure 2. Example of versions that have not been properly merged to the main record. 


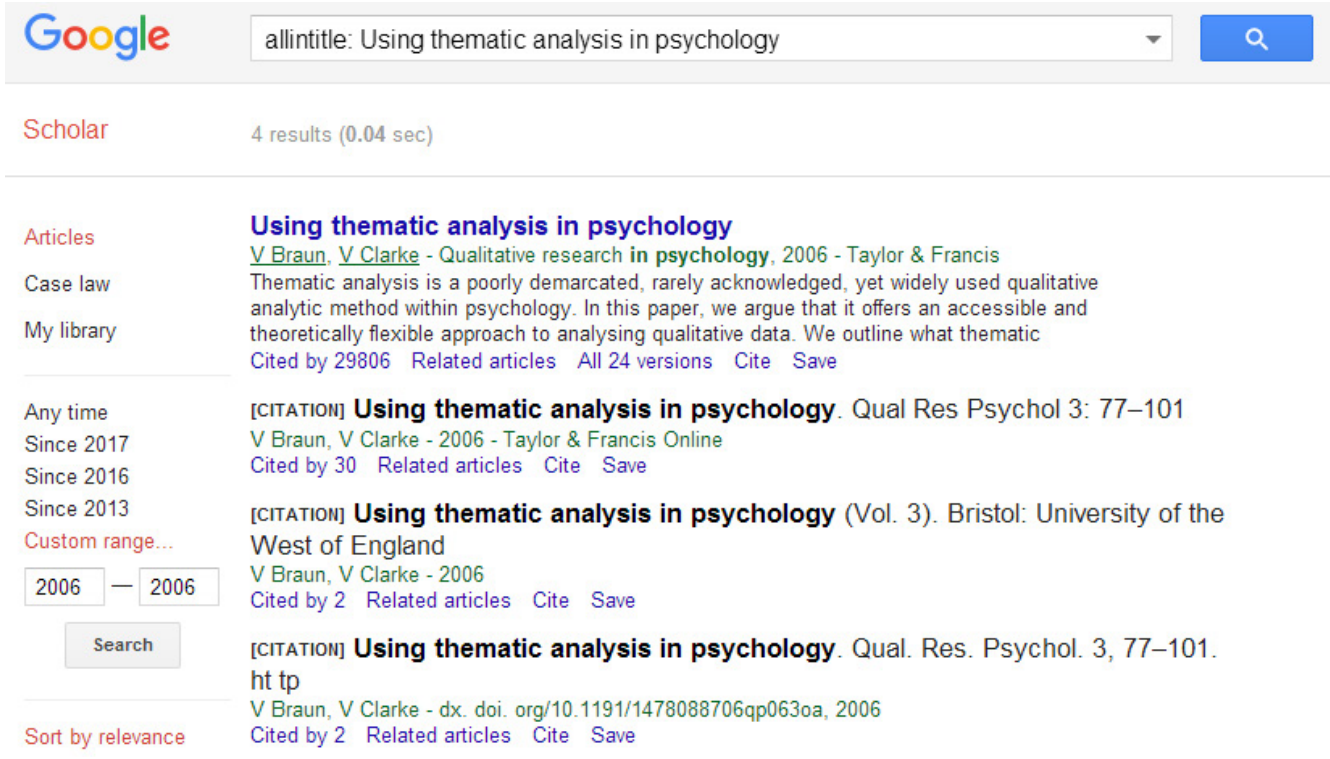

d) What is the threshold selected to visualize a "classic paper"?

Why did they decide to set this number to 10 articles in each subject category? Why is this threshold the same for the 252 subject categories?

This decision goes against logic and long-established bibliometric practices, where the different natures of the various scientific disciplines have long been acknowledged. Different scientific communities have different citation habits and different sizes in terms of number of researchers. In order to illustrate this inconsistency, the $10 \mathrm{WoS}$ categories with the highest number of papers published in 2006, and the 10 categories with the lowest number of papers published in the same year are displayed in Table 4. Next to the number of papers, another column shows the fraction that 10 articles is respect to the total amount of articles in the category.

Table 4. Number of papers classified in the 10 most productive (top) and least productive (down) WoS categories 


\begin{tabular}{|l|r|r|}
\hline \multicolumn{1}{|c}{ Web of Science Categories } & \multicolumn{1}{c}{$\begin{array}{c}\text { N } \\
\text { papers }\end{array}$} & $\begin{array}{c}\text { covered by 10 } \\
\text { documents }\end{array}$ \\
\hline Engineering Electrical Electronic & 86,568 & 0.012 \\
\hline Computer Science Artificial Intelligence & 61,137 & 0.016 \\
\hline Materials Science Multidisciplinary & 53,671 & 0.019 \\
\hline Physics Applied & 49,267 & 0.020 \\
\hline Biochemistry Molecular Biology & 47,259 & 0.021 \\
\hline Chemistry Physical & 39,715 & 0.025 \\
\hline Telecommunications & 37,641 & 0.027 \\
\hline Computer Science Theory Methods & 36,233 & 0.028 \\
\hline Optics & 33,660 & 0.030 \\
\hline Physics Condensed Matter & 32,806 & 0.030 \\
\hline
\end{tabular}

\begin{tabular}{|c|c|c|}
\hline Web of Science Categories & $\begin{array}{c}\mathbf{N} \\
\text { papers }\end{array}$ & $\begin{array}{l}\% \text { covered by } 10 \\
\text { documents }\end{array}$ \\
\hline Psychology Mathematical & 498 & 2.008 \\
\hline Primary Health Care & 484 & 2.066 \\
\hline Medical Ethics & 474 & 2.110 \\
\hline Dance & 401 & 2.494 \\
\hline Literature American & 399 & 2.506 \\
\hline Andrology & 378 & 2.646 \\
\hline Poetry & 368 & 2.717 \\
\hline Literature Slavic & 254 & 3.937 \\
\hline Folklore & 205 & 4.878 \\
\hline Literature African Australian Canadian & 175 & 5.714 \\
\hline
\end{tabular}

While in 'Engineering Electrical Electronic' and 'Computer Science Artificial Intelligence' those 10 documents make up barely $0.01 \%$ of the total, in 'Folklore' and 'Literature African Australian Canadian', 10 articles make up more than $5 \%$ of the articles in the category.

This productive disparity among disciplines goes together with also huge differences in citation patterns. The maximum and minimum number of citations in the 10 articles displayed in GSCP in the 10 categories with highest (top) and lowest (down) number of citations is shown in Table 5. This way it is easy to see the problem of selecting the same citation threshold (20) for all subject categories.

Table 5. Citations in the 10 subject categories in GSCP with highest (top) and lowest (down) numbers of citations overall. 


\begin{tabular}{|l|r|r|r|}
\hline \multirow{2}{*}{ Subcategories } & \multicolumn{3}{c}{ Citations (10 most cited articles) } \\
& Maximun & \multicolumn{1}{c|}{ Minimum } & \multicolumn{1}{c|}{ Total } \\
\hline Information Theory & 18,648 & 1,179 & 51,987 \\
\hline Psychology & 29,294 & 1,181 & 42,226 \\
\hline Cell Biology & 17,121 & 1,278 & 36,359 \\
\hline Oncology & 6,987 & 2,411 & 35,763 \\
\hline Bioinformatics \& Computational Biology & 9,981 & 1,555 & 34,680 \\
\hline Condensed Matter Physics \& Semiconductors & 8,415 & 1,640 & 34,379 \\
\hline Immunology & 5,706 & 1,706 & 23,200 \\
\hline Economics & 3,112 & 1,883 & 23,048 \\
\hline Molecular Modeling & 9,745 & 766 & 22,823 \\
\hline Astronomy \& Astrophysics & 6,624 & 1,056 & 21,854 \\
\hline
\end{tabular}

\begin{tabular}{|lrr|r|r|}
\hline \multirow{2}{*}{ Subcategories } & \multicolumn{4}{c}{ Citations (10 most cited articles) } \\
Maximun & \multicolumn{1}{c|}{ Minimum } & \multicolumn{1}{c|}{ Total } \\
\hline Literature \& Writing & 353 & 72 & 1,263 \\
\hline Visual Arts & 155 & 89 & 1,101 \\
\hline Film & 536 & 37 & 1,049 \\
\hline Technology Law & 75 & 41 & 1,014 \\
\hline European Law & 178 & 63 & 978 \\
\hline Middle Eastern \& Islamic Studies & 225 & 58 & 966 \\
\hline Canadian Studies \& History & 182 & 42 & 706 \\
\hline American Literature \& Studies & 81 & 32 & 545 \\
\hline Drama \& Theater Arts & 69 & 34 & 450 \\
\hline French Studies & 32 & 20 & 131 \\
\hline
\end{tabular}

Garfield acknowledges this problem when discussing what a "citation classic" is. He said "Citation rates differ for each discipline [...] In general, a publication cited more than 400 times should be considered a classic; but in some fields with fewer researchers, 100 citations might qualify a work" 4 . The highly cited papers available in the ESI follows the same principles delineated by Garfield. Today the product "lists the top cited papers over the last 10 years in 22 scientific fields. Rankings are based on meeting a threshold of the top $1 \%$ by field and year based on total citations received"5

\section{Conclusions}

The main advantage of GSCP is the simplicity of the product (a list of the most cited articles in each discipline, with a simple browsing interface). It is organized by broad scientific areas and inside of them by subject categories. Three clicks are enough to reach the documents or the public Google Scholar Citations profiles of their authors. Only minimal information is offered. As a whole, the product displays just over 2,500 highly cited articles. Each article presents the most basic bibliographic information.

However, despite the product is easy to use and provides original data about highly cited documents per discipline, it still suffers of some methodological concerns, mainly related to the subject classification of documents and the use of homogenous visualization threshold regardless the discipline, that jeopardizes the utility of this product for bibliometric purposes.

\footnotetext{
${ }^{4}$ Garfield, E. Short History of Citation Classics Commentaries. Available at http://garfield.library.upenn.edu/classics.html

${ }^{5} \mathrm{https}$ ://images.webofknowledge.com/images/help/WOS/hs_citation_applications.html
} 
In addition to this, the lack of transparency constitutes a methodological concern, since Google Scholar does not declare in detail how the product has been developed.

\section{Acknowledgements}

Alberto Martín-Martín enjoys a four-year doctoral fellowship (FPU2013/05863) granted by the Ministerio de Educación, Cultura, y Deportes (Spain).

\section{References}

Bornmann, L. (2014). How are excellent (highly cited) papers defined in bibliometrics? A quantitative analysis of the literature. Research Evaluation, 23(2), 166-173.

Garfield, E. (1971). Citation indexing, historio-bibliography and the sociology of science. Current Contents, 6, 156-157.

Garfield, E. (1974). Selecting the All-Time Citation Classics. Here Are the Fifty Most Cited Papers for 1961-1972. Current Contents, 2, 5-8.

Garfield, E. (1977). Introducing Citation Classics: The human side of scientific papers. Current Contents, 1, 5-7.

Martín-Martín, A.; Ayllón, Juan M.; Orduna-Malea, E. \& Delgado López-Cózar, E. (2014). Google Scholar Metrics 2014: a low cost bibliometric tool. EC3 Working Papers, 17.

Martín-Martín, A., Ayllón, Juan M., Delgado López-Cózar, E., \& Orduña-Malea, E. (2015). Nature 's top 100 Re-revisited. Journal of the Association for Information Science and Technology, 66(12), 2714-2714.

Martin-Martin, A., Orduna-Malea, E., Harzing, A.W., \& Delgado López-Cózar, E. (2017). Can we use Google Scholar to identify highly-cited documents?. Journal of informetrics, 11(1), 152-163.

Orduna-Malea, E., \& Delgado López-Cózar, E. Dimensions: re-discovering the ecosystem of scientific information. El Profesional de la Información, 27(2), 420-431.

Orduna-Malea, E., Martín-Martín, A., Ayllón, Juan M., \& Delgado López-Cózar, E. (2016). La revolución Google Scholar: Destapando la caja de Pandora académica. Granada: Universidad de Granada. 


\section{STI 2018 Leiden}

\section{3rd International Conference on Science and Technology Indicators "Science, Technology and Innovation Indicators in Transition"}

\section{STI 2018 Conference Proceedings}

Proceedings of the 23rd International Conference on Science and Technology Indicators

All papers published in this conference proceedings have been peer reviewed through a peer review process administered by the proceedings Editors. Reviews were conducted by expert referees to the professional and scientific standards expected of a conference proceedings.

\section{Chair of the Conference}

Paul Wouters

\section{Scientific Editors}

Rodrigo Costas

Thomas Franssen

Alfredo Yegros-Yegros

\section{Layout}

Andrea Reyes Elizondo

Suze van der Luijt-Jansen

The articles of this collection can be accessed at https://hdl.handle.net/1887/64521

ISBN: 978-90-9031204-0

(c) of the text: the authors

(c) 2018 Centre for Science and Technology Studies (CWTS), Leiden University, The Netherlands

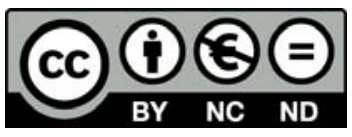

This ARTICLE is licensed under a Creative Commons Atribution-NonCommercial-NonDetivates 4.0 International Licensed 